\title{
AS RELAÇÕES PATRIARCAIS DE GÊNERO NA FAMÍLIA: INFLUÊNCIA DA MÍDIA TELEVISIVA
}

\author{
P. P. T. ALCANTARA*, C. L. PEIXOTO, A. M. S. SILVA \\ Universidade Federal do Cariri \\ enfermeira.tavares.81@gmail.com
}

\section{RESUMO}

O presente estudo tem como objetivo a reflexão sobre as relações patriarcais de gênero refletidas na família através da mídia televisiva. Partindo do pressuposto de que estas relações encontram-se naturalizadas na sociedade. Sua origem é retrógrada, remota ao surgimento da propriedade privada e da monogamia, como bases de sustentação do sistema patriarcal (Saffioti, 2004). Este sistema organiza as relações de opressão-exploração das mulheres, instituindo papéis sociais e sexuais a serem cumpridos por ambos os sexos. Estes papéis são reproduzidos em todos os segmentos sociais, inclusive nos meios de comunicação, em especial a televisão, fonte de acessibilidade em massa (Engels, 2007). O estudo fora realizado numa abordagem bibliográfica, com o intuito de reflexão e conhecimento para uma possível transformação da realidade e visibilidade das relações patriarcais de gênero.

PALAVRAS-CHAVE: Patriarcado, Gênero, Papéis Sociais, Mídia Televisiva.

\section{THE PATRIARCHAL GENDER RELATIONS IN THE FAMILY: INFLUENCE OF TELEVISION MEDIA}

\begin{abstract}
The present study aims to reflect on the patriarchal gender relations reflected in the family through the television media. On the assumption that these relations are embedded in society. Its origin is retrograde, remote appearance of private property and of monogamy, as support bases of the patriarchal system (Saffioti, 2004). This system organizes the relations of oppression-exploitation of women,
\end{abstract}

instituting social roles and sexual to be met by both sexes. These roles are played in all social segments, including in the media, in particular television, source of mass accessibility (Engels, 2007). The study was carried out in a bibliographical approach, with the aim of reflection and knowledge for a possible transformation of reality and visibility of patriarchal gender relations. 


\section{INTRODUÇÃO}

O patriarcado está presente em todas as relações sociais e também no meio em que estas se propagam. Um tipo de meio está direcionado à comunicação, à mídia televisiva. Esta contribui na formação da identidade social e pode ser de grande ameaça ao reproduzir diariamente em sua programação cenas que reforçam estereótipos de "mulher dona de casa" , "mulher gostosa", "mulher burra". A TV é um grande veículo de comunicação, e ao mesmo tempo em que emancipa, ela também aliena.

A questão é que as relações patriarcais de gênero parece não ser um problema. Os indícios são de que elas existem desde o início da família monogâmica e por ser algo tão antigo acabou se naturalizando dentro da sociedade. A justificativa da criação de regras, de normas, de valores, de papéis sociais diferentes para homens e mulheres é condicionada pelo aspecto biológico. A ênfase na aparência e nos órgãos sexuais serve de explicação para o sistema de dominação-exploração (Avelar, 2010).

A perspectiva consiste em discutir patriarcado, gênero e mídia televisiva, através de uma pesquisa bibliográfica proporcionando o conhecimento dos avanços nos estudos sobre gênero. A relevância consiste na reflexão sobre a invisibilidade destas influências reproduzidas pela mídia televisiva, que acabam por naturalizar qualquer forma de subordinação e preconceito implicando no desmonte dos direitos humanos e civis, e deixando aberta a porta da violência.

O presente trabalho tem como objetivo a reflexão sobre as relações patriarcais de gênero refletidas na família através da mídia televisiva.

\section{CONSTRUÇÃO SÓCIO-HISTÓRICA DO PATRIARCADO}

A compreensão do patriarcado consiste em estabelecer as desigualdades existentes nas relações sociais entre homens e mulheres. Enquanto sistema de dominação-exploração presente desde tempos remotos é evidente a sua existência ainda na atualidade. Para explicar sua origem, esta pesquisa remete-se primeiramente aos estudos elaborados por Engels (2007) em sua obra $A$ origem da família da propriedade privada e do Estado. Aqui o autor tem como figuras referenciais estudos de antropólogos e o materialismo histórico.

Baseado na figura central de Morgan, Engels atribui o desenvolvimento humano atrelado as mudanças nos meios de produção. A concepção materialista vai mostrar que a causa das transformações, tanto para suprir as necessidades básicas como econômicas advém do trabalho. Para Engels (2007):

De acordo com a concepção materialista, o fator decisivo na história é, em última instância, a produção e a reprodução da vida imediata. Mas essa produção e essa reprodução são de dois tipos: de um lado, a produção dos meios de existência de produtos alimentícios, habitação, e instrumentos necessários para tudo isso; de outro lado, a produção do homem mesmo, a continuação da espécie. A ordem social em que vivem os homens de determinada época ou determinado país está condicionada por essas duas espécies de produção: pelo grau de desenvolvimento do trabalho, de um lado, e da família do outro.

Em seu livro, Engels (2007), descreve a família através de fases de forma didática considerando o sistema de parentesco, o matrimônio e o incesto para a sua organização. Estas fases vão corresponder aos três estágios pré-históricos da cultura que Morgan chama de estado 
selvagem, barbárie e civilização. A primeira forma de família é a Consangüínea, excluía os pais das relações sexuais recíprocas. A segunda família era a Punaluana, além de excluir os pais, também excluía irmãos. O matrimônio era grupal, homens e mulheres se pertencem mutuamente. A terceira forma de família era a Sindiásmica, em que já começava a prevalecer o matrimônio por pares, mas a poligamia prevalecia entre os homens. Aqui, ainda se constitui a verdadeira mãe, mas não a figura do verdadeiro pai. Esta família vai permitir o desenvolvimento da família monogâmica e do patriarcado, por conta do progresso econômico.

O patriarcado surge da passagem da família sindiásmica para a família monogâmica com o incremento da propriedade privada. As produções dos meios de existência e de seu excedente produziam riqueza, que à medida que aumentavam, davam ao homem uma posição mais importante do que a da mulher dentro da família. Busca-se ter uma paternidade indiscutível, pois na condição de herdeiros, seus filhos deveriam ter um dia a posse de seus bens. Este período fica marcado como "a grande derrota histórica do sexo feminino em todo mundo" (Brabo, 2010).

Já para Coulanges (1960) no seu estudo das sociedades greco-romana, afirma que quem estabeleceu a família, a autoridade paternal, as linhas de parentesco, o direito a propriedade foi a religião primitiva. Aqui a herança e o parentesco serão regulamentados pela participação no culto. Ele leva em conta para sua formação, os aspectos sociais e culturais deixando de lado os aspectos materialistas, ou seja, a base econômica da sociedade.

Este mesmo autor mostra que a descoberta da paternidade advém de quando os homens abandonaram a caça, por conta da extinção dos animais e começaram a participar das atividades das mulheres na agricultura e domesticação de animais. Foi na convivência com os bichos que os homens começaram a perceber que o macho contribuía para a procriação. E mais, um só macho podia emprenhar várias fêmeas. Com isto a reação masculina não foi das melhores, era como se homem tivesse sendo enganado, já que antes a fertilidade era somente uma característica feminina. E começou a eclodir um comportamento autoritário e arrogante, a superioridade física encontra espaço para se estender à superioridade ideológica. Além de criar o filho, o homem também passa a criar a mulher. Teve seu domínio ampliado.

Na monogamia é exigido da mulher castidade e fidelidade, não enquadrando homens. A fim de assegurar isto, é aqui que se configura o controle da sexualidade. É exemplo o que Saffioti (2004) aborda sobre a mutilação feminina, prática que ocorre em países da África e da Ásia, onde meninas ainda crianças, têm extirpados seus clitóris, lábios vaginais internos e externos, a fim de reduzir o prazer sexual e tornar a relação uma verdadeira tortura.

Fica claro que a monogamia "surge sob a forma de escravização de um sexo pelo outro". Juntamente com Marx, Engels acrescenta que foi em razão disto que surgiu o primeiro antagonismo de classes, configurado pela a opressão do sexo feminino pelo masculino. Conhecida como estado civilizado e também como início da escravidão e das riquezas privadas, nesta organização de família o "progresso é simultaneamente um retrocesso relativo, e o bemestar e o desenvolvimento de uns se verificam às custas da dor e repressão de outros" (Engels, 2007).

Endossado nestes pensamentos é considerado um equívoco "colocar o nome da dominação masculina - patriarcado - na sombra significa operar segundo a ideologia patriarcal, que torna natural essa dominação-exploração" (Saffioti, 2004).

Esta naturalização tem sentido com o que Almeida (2010) esclarece que este processo torna o fenômeno invisível, para que se possa continuar presente na sociedade sem ser contestado, "nem se quer a presença do patriarca é imprescindível para mover a máquina do patriarcado". Daí se tem a ideia de que o patriarcado não existe mais na atualidade, o seu conceito restrito de dominação baseado na figura do pai, deixa estes resquícios. 
Para Saffioti (2004), o patriarcado não deixou de existir, apenas está em constante transformação.

Cumpre frisar a particularidade que luta contra essa dominação, o movimento feminista. Busca a equidade e a justiça nas relações de homens e mulheres. A desnaturalização de toda e qualquer forma de opressão e discriminação, romper com estereótipos e papéis sociais que deixam a mulher numa condição desprivilegiada, secundária e de violência (Almeida, 2010).

O feminismo faz uma crítica às teorias que condizem com o sistema de dominação. Segundo Lisboa (2010) projetam teorias interdisciplinares e contemporâneas. Insere-se no âmbito da categoria gênero, investigando experiências masculinas e femininas, voltadas principalmente numa perspectiva onde a mulher esteja no centro.

\title{
3 EM QUE A CATEGORIA GÊNERO SE DISTINGUE DO PATRIARCADO?
}

O patriarcado se estruturou ao longo dos anos como a dominação das mulheres pelos homens. Na atualidade organiza não só as relações de gênero como também toda forma de dominação da sociedade, como cultura, Estado, mídia e religião. Estas relações não são de fato naturais, são relações construídas ao longo da história pela sociedade para designar o que é ser homem e o que é ser mulher. Pode-se dizer que "o conceito de gênero é mais amplo que a noção de patriarcado" (Saffioti, 2004).

Exemplos claros sobre o que é ser homem e o que é ser mulher são quando ainda na infância escutamos de nossos pais e dos mais velhos coisas do tipo "mulher que é mulher senta de perna fechada" ou então "homem que é homem não chora, tem que dar no couro". Os elementos básicos das diferenças entre gênero e patriarcado são os que Saffioti (2004) mostra em seu texto:

\begin{abstract}
Gênero é um conceito por demais palatável, porque é excessivamente geral, a-histórico, apolítico e pretensamente neutro. Exatamente em razão da sua generalidade excessiva, apresenta alto grau de extensão, mas baixo nível de compreensão. O patriarcado ou ordem patriarcal de gênero, ao contrário, como vem explícito em seu nome, só se aplica a uma fase histórica, não tendo a pretensão da generalidade nem da neutralidade, e deixa propositadamente explícito o vetor da dominaçãoexploração. Perde-se em extensão, porém se ganha em compreensão.
\end{abstract}

Gênero é uma categoria que deixa aberto o vetor dominação-exploração, ou seja, termos como patriarcado marcam somente a presença masculina, mas no primeiro não existe primazia aos homens ou às mulheres, posto que regula as relações homem-mulher, homem-homem e mulher-mulher. Começando por um simples conceito "gênero é a construção histórica do feminino e do masculino" (Saffioti, 2004). Vale salientar que para a autora esta categoria transcorre todas as classes sociais, como também a discriminação racial.

\section{COMPREENDENDO OS PAPÉIS SOCIAIS DE HOMENS E MULHERES NA SOCIEDADE}

A construção social de homens e mulheres é distinta. Saffioti (1987) mostra que os papéis sociais são os campos em que homens e mulheres podem operar delimitados pela sociedade. 
Esta por sua vez cria o processo de naturalização que é atribuído de diferentes maneiras em diversos lugares.

Sobre isto, Bourdieu (2003) fala:

A divisão entre os sexos parece estar na "ordem social das coisas", como se diz por vezes para falar do que é normal, natural, a ponto de ser inevitável: ela está presente, ao mesmo tempo, em estado objetivado nas coisas (na casa, por exemplo, cujas partes são todas "sexuadas"), em todo o mundo social e, em estado incorporado, nos corpos e nos habitus dos agentes, funcionando como sistemas de esquemas de percepção, de pensamento e de ação.

Essa construção é oriunda das condições biológicas, ou seja, a ênfase nos órgãos reprodutivos, a aparência frágil, vem pra justificar a situação em que a mulher se encontra subordinada ao homem e que é naturalizada. "O mundo social constrói o corpo como realidade sexuada e como depositário de princípios de visão e de divisão sexualizantes" (Bourdieu, 2003). Esta divisão implica em um processo sociocultural, que cada sociedade assimila de forma diferente de outras sociedades, ou seja, cada sociedade tem o seu princípio social e cultural.

$\mathrm{Na}$ frase de abertura do volume dois do livro O Segundo Sexo da autora Simone de Beauvoir (1967) deixa claro que o processo social permite o ser homem e o ser mulher, mas que ambos nascem machos e fêmeas.

Ninguém nasce mulher: torna-se mulher. Nenhum destino biológico, psíquico, econômico define a forma que a fêmea humana assume no seio da sociedade; é o conjunto da civilização que elabora esse produto intermediário entre o macho e o castrado que qualificam de feminino.

Para Saffioti (1987) o argumento biológico só é utilizado, porque não existe nenhum fundamento científico que comprove a ideologia de que a mulher é inferior ao homem.

Para Louro (1987) os papéis sociais são padrões estabelecidos por membros da sociedade para definir comportamentos, modos de se relacionar, de se portar ou de se vestir. É considerar o que é adequado e inadequado para homens e mulheres que devem responder a essas expectativas.

As mulheres são atribuídos papéis de mães e donas de casa, aos homens ficam as obrigações do sustento e de chefiar a família. As primeiras estão destinadas a conviver num espaço privado ou doméstico. Os segundos se encarregam do público, de trabalhar fora para manter o sustento da família. Quando a mulher trabalha fora do lar ou quando o homem trabalha dentro do espaço doméstico, essas tarefas se configuram como "ajuda". E "sempre que a atividade de alguém se configura como ajuda, a responsabilidade é do outro" (Beleli, 2010).

Considerando o homem um ser superior à mulher, esta a assimila, de maneira que não precisa do homem para mover a máquina do machismo. Sendo assim, as mesmas contribuem para sua disseminação, tendo em vista, que através da educação repassam aos seus filhos tais valores, quando proíbem os meninos chorarem, pois "homem não chora" ou quando exigem das filhas que se comportem como mocinhas, ao sentarem de pernas fechadas. Esses valores interferem sobremaneira na inculcação dos papeis sociais e sexuais que homens e mulheres devem exercer na sociedade, a partir disso, devemos considerar que gênero corresponde a sexualidade social e sexo a esfera biológica, apesar de ambos serem constituídos como inseparáveis, tendo em vista que o ser é unívoco (Saffioti, 2004). 


\section{MÍDIA TELEVISIVA: MECANISMO DA SOCIEDADE QUE CONTRIBUI PARA A DISSEMINAÇÃO DAS RELAÇÕES PATRIARCAIS DE GÊNERO}

A representação da imagem feminina na mídia televisiva não é diferente da que vimos anteriormente nos papéis sociais. Ainda que seja uma representação retrógrada, no século XXI é comum encontrar a mesma atribuição machista à mulher. São discursos que passam despercebidos, já que é normal para todos ver na imagem feminina uma dona de casa, uma mãe ou um objeto de desejo (Lisboa, 2010).

A televisão é um mecanismo que influencia e capta comportamentos e valores de propagandas, programas e novelas que são assimilados pelos telespectadores na vida real. Muitas de nossas opiniões são formadas a partir do que vemos e a televisão age como "a opinião pública". Segundo Moreno (2007) nela é exibido modelos e valores que identificamos como nosso e que constituem nosso padrão aspiracional. A imagem da mulher quando não acusa invisibilidade, vem relacionada a estereótipos do tipo "bela e burra" e "boa".

De acordo com Moraes (2002) este tipo de mídia é a mais poderosa e a mais popular, pois mesmo nas menores e mais pobres cidades se pode ter acesso a TV. Ela alcança tanto pessoas alfabetizadas como analfabetas. Além de entreter, também proporciona uma teia de poder, em que a maior credibilidade é dada ao homem. Como diz a autora "o homem está intimamente ligado ao respeito social". É comum que até em propagandas relacionadas a materiais de limpeza, que são feitas por mulheres, se escute a voz do homem confirmando a boa qualidade do produto.

Ainda com base na autora a imagem da mulher jovem é mais utilizada. A sua figura passa sensualidade, desejo e glamour. A mulher em sua fase avançada passa dignidade, ou melhor, respeito. Mas a da meia-idade parece uma piada de mau gosto, pois para muitas atingir 40 ou 50 anos é muito complicado, é sempre alvo de estereótipos. Já os homens nesta idade apresentam características de bem-sucedido e de charmosos, em propagandas, principalmente de carros, estão sempre acompanhados de lindas e jovens mulheres que geralmente permanecem caladas como se fossem parte do cenário. "A meia-idade feminina parece não vender nem desodorantes, nem viagens fantásticas, nem sabonetes e muito menos cremes de beleza" (Moraes, 2002).

No artigo "Os Arquétipos nas Propagandas de Revistas Femininas" do autor Silva (2010) são traçados três perfis para a imagem feminina: a Grande Mãe, a Donzela/Prostituta e a Guerreira. O primeiro perfil dos anos sessenta até atualidade vem sendo pouco modificado. Aqui as propagandas estão sempre relacionadas à mulher dona-de-casa que com o decorrer do tempo vira uma supermulher que além de cuidar da casa também tem um emprego. $O$ segundo perfil no começo a mulher não tem a imagem de sedutora, até porque ela é muito mais mãe do que mulher. São consideradas meigas, estéreas, recatadas e elegantes.

O desejo de se libertar, de tomar as rédeas de sua própria vida e também o discurso da igualdade entre os sexos fez nascer uma mulher que trazia no corpo a sua arma de sedução, onde as propagandas estavam mais provocativas, poses sensuais, bocas entreabertas, usando unhas, roupas e batons vermelhos, cor que simboliza a liberdade sexual. Ela usa e abusa do poder da atração. O último perfil a imagem feminina é marcada por anúncios de uma mulher trabalhadora, que tem serviços extra lar. Tem atitudes para ser uma mulher forte e independente, ligadas a coragem, a bravura, a luta e a persistência (Almeida, 2010).

Não bastasse tudo isso, a sua figura ainda vem acoplada a traços culturais. O Brasil carrega consigo a natureza exótica e receptiva da mulher, também é conhecido como "o país da bunda". É comum em diversas propagandas que vai de pacotes de viagem até a venda de bebidas alcoólicas mostrarem que aqui é um lugar em que se possa realizar fantasias e desejos, induzem 
turistas a virem ao Brasil para fazerem sexo com as belas mulheres com aspecto sexual (Lisboa, 2010).

Sobre isto, a autora Beleli (2010) faz uma crítica a propaganda da Marie Claire, onde tem como logotipo "Levanta Brasil", com a imagem de uma mulher de costas exibindo quadris bem largos. A forma do corpo exibe a preferência nacional, na campanha "há uma associação direta entre a parte do corpo feminino e a nação, onde a combinação Bunda-Brasil assume a sua forma explícita".

A publicidade feita nas propagandas de cerveja é sempre dirigida ao público masculino. Concentra vários homens em torno de uma mulher, que no caso é a mulher, sempre representada por uma atriz ou modelo que tem um corpo exuberante, de acordo com os padrões estabelecidos por este meio. Ou às vezes concentra várias mulheres em torno de um homem, que não está dentro dos padrões de beleza, mas que passa a imagem de ter a mulher que quiser só porque está consumido o produto. $\mathrm{O}$ grande número de figurantes serve para que se tenha a ideia de que o produto foi aprovado. Segundo Silva (2010):

[...] a personagem feminina situa-se novamente como objeto de prazer do homem, mas não a mulher inteira, completa, mas uma parte dela se torna o fetiche do prazer, pois a propaganda lança mão da atração que o brasileiro tem pelas nádegas femininas.

Essa indústria cultural visa a expansão do mercado consumidor. Introduz uma série de inovações tecnológicas orientadas por interesses capitalistas que visam a ampliação e o controle deste mercado, buscando na imagem feminina a propagação de seus produtos.

As redes de televisão estimulam a entrada de capital. A telenovela sendo um de seus produtos de grande audiência é o mais explorado para difundir valores, ideias e mercadorias, na sua exibição ou nos intervalos dos capítulos. Trabalha com padrões de comportamento e relações sociais, que constituem o espelho do sistema econômico que a sociedade adquire (AVELAR, 2010).

Para Brabo (2010) a mudança nas relações sociais e a garantia dos direitos não são valorizadas pela mídia. A TV ainda contribui para subordinar e inferiorizar a mulher. A globalização e suas revoluções tecnológicas estão deixando mais longe a concretização de um ideal de sociedade democrática, pela perda da interação coletiva, do sentido de uma cultura pública, pela tendência ao individualismo e pelo ideário neoliberal.

\section{CONSIDERAÇÕES FINAIS}

A televisão é um meio de comunicação que envolve a sociedade, e introduz valores e comportamentos que vão refletir diretamente no modo de vida de cada pessoa. Temos sempre a impressão de que tudo que se vê é verdade. Essa alienação produz grandes impactos, principalmente quando se caracteriza como uma violência. Daí se tem a necessidade da interferência de profissionais qualificados e movimentos que lutam a favor da igualdade, com visão crítica que possa atender tais demandas, assinaladas por sua invisibilidade.

Os movimentos feministas constantemente se engajam em lutas para desvendar e tornar visível a hierarquização e o preconceito. Alguns autores como Brabo (2010), citado no texto, fala que estes movimentos sustentam que a mídia reforça a opressão e é a chave na modelagem das relações de gênero. 
Logo, é importante ler e debater acerca deste assunto para que a luta ocorra, pois é comum vermos movimentos sem respaldo devido a falta de conhecimento, que acabam por deixar no ridículo toda uma categoria de profissionais que fazem um trabalho digno.

\section{REFERÊNCIAS}

ALMEIDA. J. P. de. (2010). As multifaces do Patriarcado: uma análise das relações de gênero nas famílias homoafetivas. Recife: O Autor.

AVELAR. M. de F. (2010). Mídia e construção de identidades sociais. In: Gênero, educação, trabalho e mídia. São Paulo: Ícone.

BEAUVOIR, S. de. (1967). O segundo sexo 2: A experiência vivida. 2ª̣ed., tradução Sergio Milliet. Difusão Européia do Livro, São Paulo.

BELELI, I. (2010). Mulheres e relações de gênero: poder simbólico, mídia e arte. In: Gênero, educação, trabalho e mídia. São Paulo: Ícone.

BOURDIEU, P. (2003). A dominação masculina. Tradução Maria Helena Kühner. 3a ed., Rio de Janeiro: Bertrand Brasil.

BRABO, T. S. A. M. (2010). Movimento feminista e mídia encontros e desencontros. In: Gênero, educação, trabalho e mídia. São Paulo: Ícone.

COULANGES, F. de. (1961). A cidade antiga. São Paulo: Editora das Américas.

ENGELS, F. (2007). A origem da família, da propriedade privada e do Estado. Tradução de Leandro Konder. 17a Ed. Rio de Janeiro: Bertrand Brasil.

LISBOA, T. K. (2010). Gênero, feminismo e Serviço Social: encontros e desencontros ao longo da história da profissão. Rev. katálysis [online]. vol.13, n.1.

LOURO, G. (1997). Gênero, sexualidade e educação. Petrópolis: Vozes.

MINAYO, M. C. S. (1996). Pesquisa social: teoria, método e criatividade. 5a ed., Petrópolis: Vozes.

MORAES, M. (2002). Ser humana: quando a mulher está em discussão. Rio de Janeiro: DP\&A.

MORENO, R. (2007). A mulher na tv. Folha feminista. Boletim da SOF na luta feminista. Junho 2007. no 64.

SAFFIOTI, H. I. B. (2004). Gênero, patriarcado, violência. São Paulo. Editora Fundação Perseu Abramo. (1987). O poder do macho. 3 ed. São Paulo: Moderna.

SILVA, S. G. da. (2010). Preconceito e discriminação: as bases da violência contra a mulher. Psicol. cienc. prof. [online]. vol.30, n.3, pp. 556-571. 